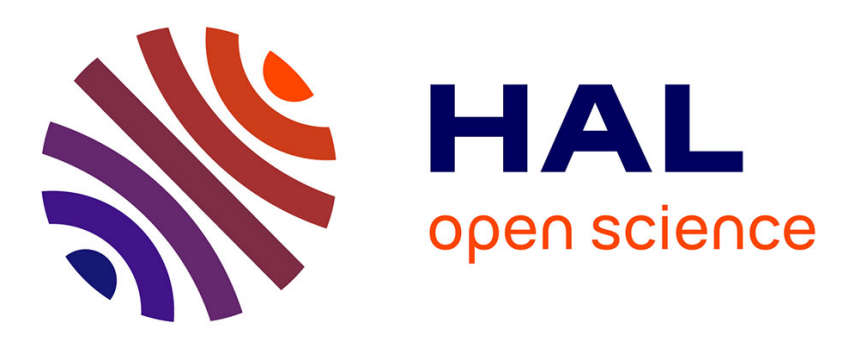

\title{
Modification of the porous network by salt crystallization in experimentally weathered sedimentary stones
}

Matthieu Angeli, David Benavente, Jean-Philippe Bigas, Beatriz Menendez, Ronan Hébert, Christian David

\section{To cite this version:}

Matthieu Angeli, David Benavente, Jean-Philippe Bigas, Beatriz Menendez, Ronan Hébert, et al.. Modification of the porous network by salt crystallization in experimentally weathered sedimentary stones. Materials and structures, 2008, pp.only online for the moment. 10.1617/s11527-007-9308-z . hal-00239443

\section{HAL Id: hal-00239443 \\ https://hal.science/hal-00239443}

Submitted on 5 Feb 2008

HAL is a multi-disciplinary open access archive for the deposit and dissemination of scientific research documents, whether they are published or not. The documents may come from teaching and research institutions in France or abroad, or from public or private research centers.
L'archive ouverte pluridisciplinaire $\mathbf{H A L}$, est destinée au dépôt et à la diffusion de documents scientifiques de niveau recherche, publiés ou non, émanant des établissements d'enseignement et de recherche français ou étrangers, des laboratoires publics ou privés. 


\title{
Modification of the porous network by salt crystallization in experimentally weathered sedimentary stones
}

\author{
Matthieu Angeli ${ }^{1}$, David Benavente ${ }^{2}$, Jean-Philippe Bigas ${ }^{1,3}$, Béatriz Menéndez ${ }^{1}$, Ronan \\ Hébert $^{1}$ and Christian David ${ }^{1}$ \\ 1 Laboratoire de Tectonique, Université de Cergy-Pontoise, CNRS, UPMC; 5, mail Gay- \\ Lussac, Neuville-sur-Oise 95031 Cergy-Pontoise - France \\ 2 Departamento de Ciencias de la Tierra y del Medio Ambiente, Laboratorio de Petrologia \\ Aplicada, Universidad de Alicante, Apartado Correo 99, 03080 Alicante, España \\ 3 Chryso, 7 rue de l’Europe, 45300 Sermaises, France
}

\begin{abstract}
The aim of this study is to understand how the porous network of a stone is modified by the crystallization of sodium sulphate. Samples of five different stones have been experimentally weathered and evaluated thanks to mercury porosimetry in three different states: fresh, weathered by salt, and weathered cleaned from the salts. Optical and electronic microscopy observations have also been led to complete these measurements. The results show that porosity and the general aspect of the porous network remain quite similar after weathering. Nevertheless, crystals tend to grow on all the grains regardless of the size of the related voids (pores or cracks), and these crystallizations seem to be harmful for the stone: a lot of voids of different entry sizes (from 10nm to $20 \mu \mathrm{m}$ ) have been affected during the accelerated ageing tests. This study confirms that generally stones with a high amount of small pores (up to several $\mu \mathrm{m}$ ) are the most susceptible to suffer from salt damage. Nevertheless, the influence of a few other features (high porosity, pore shape, pre-existent intragranular cracks) on the long-term behaviour of the stones suffering from salt decay is discussed.
\end{abstract}

\section{Introduction}

Salts, and particularly sodium sulphate, are known to be among the most destructive agents in porous stones, concrete or brick weathering. Their study is thus very important to fully understand their crystallization process in porous networks and, in the future, to find a way to prevent or limit their damage to porous materials. Recent studies attribute the decay to the salt crystallization pressure of mirabilite $\left(\mathrm{Na}_{2} \mathrm{SO}_{4} \cdot 10 \mathrm{H}_{2} \mathrm{O}\right)$, rather than thenardite $\left(\mathrm{Na}_{2} \mathrm{SO}_{4}\right)$ (Rodriguez-Navarro \& Doehne 1999, Scherer 1999, Flatt 2002, Benavente et al. 2004a, Steiger 2005a,b). This damage depends on numerous factors: the type and quantity of salt in the stone, the characteristics of the porous network, the environmental conditions (a complete review can be found in Ruiz-Agudo 2007). The aim of this study is to understand how the porous network of the stone can be modified by crystallization of salts in pores. Mercury porosimetry will help to find in which range of pore entry size sodium sulphate crystallizes, what is the size of the new cracks due to crystallization pressure, and if these characteristics differ from one stone to another, that is to say to what extend salt damage depends on the porous network of the stones. This will help to have an experimental illustration of the thermodynamical theories about crystallization of salts in pores (Scherer 2004; Steiger 
2005a,b; Coussy 2006) in order to enhance the general comprehension of the process, and in the longer term find a way to reduce their damage.

Several studies have already been led to understand the influence of the stone microstructures on its durability to salt weathering. Russell (1927) was the first to introduce the idea that the stones with the most micropores are the most susceptible to salt decay. This idea has been confirmed later by other studies (Schaffer 1932; Honeyborne and Harris 1958; Fitzner and Snethlage 1982).

Fitzner (1988) compared the porous network from different samples of Schilfsandstein, a german sandstone. One sample was fresh from the quarry; one was taken from a building, and the last one came from the flaking of the stone. He concludes that pores with entries under $100 \mathrm{~nm}$ are unchanged, and that the mean size of the pores rises. Fitzner (1988) concluded that pores with entries under $100 \mathrm{~nm}$ are not reached by the fluids, and that the pore size raise is due to the progressive destruction of grains.

Benavente et al. (1999) has worked on 3 different types of Bateig stone with porosity around $15 \%$ (white, blue and layered) and a quartzarenite with $6.4 \%$ total porosity. The authors compared the size of the pore entry for fresh samples and experimentally weathered samples cleaned from salt (sodium sulphate). They have observed that the porosity and pore size raises more for stones with a high proportion of pores from 0.1 to $2500 \mu \mathrm{m}$. In this range of pore size, as the flow is governed by capillarity, the brine flows easily and thus successions of imbibitions and dryings occur more easily, which increases significantly the number of possible crystallization. They also concluded, like Fitzner (1988), that damage associated with in the smallest pores (under $0.1 \mu \mathrm{m}$ ) is difficult to observe. A solution to this problem would be to use helium pyknometry and compare it to mercury porosimetry to see how these smallest pores are affected by salt weathering.

Such a comparison has been undertaken by Dei et al (1999) on four different building stones with relatively low porosity: two stones of clastic origin (Pietraforte and Firenzuola stone) with total porosity around $8 \%$ and two carbonatic stones with very low porosity: Travertine and Carrara marble (resp. 4.4 and 2.7\%). The accelerated salt weathering experiments have been performed with $\mathrm{KNO}_{3}$, and the weathered samples have not been cleaned from salt before mercury porosimetry and helium pyknometry testing. The mean pore size rose for the 4 stones used. According to the authors, the crystals of $\mathrm{KNO}_{3}$ grow not only beneath the external surface of the sample but also deeper within the porous structure. These crystals tend to grow in large pores and close the entrance of small pores, which become undetectable to mercury porosimetry.

Rodriguez-Navarro and Doehne (1999) have worked on an oolithic limestone widely used as a building stone in the United Kingdom: the Monks Park stone. They used both sodium sulphate and chloride for their accelerated weathering tests. This stone has a porosity of $20.0 \%$ and a mean pore radius between 0.20 and $0.30 \mu \mathrm{m}$. After the tests, the samples tested with sodium chloride were slightly destroyed compared to the samples tested with sodium sulphate which presented contour scaling and lost up to $20 \%$ of their initial weight. The mercury porosimetry tests performed with the salts still in the porous network showed that the porosity has not really changed with sodium sulphate. The peak of pore entry around $1 \mu \mathrm{m}$ has slightly shrunk and shifted to smaller values indicating that a large part of the pore entries has been slightly obstructed by the crystals of sodium sulphate. Nevertheless, the sodium chloride has filled all the smaller pores of the stones (entry under $0.2 \mu \mathrm{m}$ ), and thus reduced the 
porosity to its half. The reason why it damages less Monks Park limestone is because sodium chloride reaches lower supersaturation ratios, and thus lower crystallization pressure (Correns 1949). The authors indicate that supersaturation during drying takes place in the smaller pores where higher crystallization ratios can be achieved, the larger ones acting like reservoir to supply the solution. According to them, this explains why stones with a large proportion of micropores connected to large pores are very sensitive to weathering (Everett, 1961). These conclusions are a bit different from Dei et al. (1999) who suggest that there are more damages when crystals grow in large pores, close to the entrance of small ones.

\section{Materials and Methods}

\section{Materials}

Five stones from different lithologies have been used in this study: two limestones and three sandstones. The analysis of the damage has also been performed on two other sandstones. The two limestones are of lutetian age: the "roche fine" (FL) and the "liais" (LL). These limestones come from the Parisian basin. They have high porosity compared to the other stones in this study (respectively 36.1 and 17.0\%). FL is a detritic limestone made of calcite grains (90\%) and quartz (10\%). It contains lots of microfossils (mainly nummulites). Its tensile strength is very low (1.5 MPa). LL is a biodetritic composed by more than $90 \%$ of calcite, with traces of iron oxides. It also contains some microfossils like nummulites, but also numerous macrofossils (bivalves, gasteropods) giving to the stones a heterogeneous aspect. During diagenesis, which was very similar for both stones since they come from the same quarry, secondary micrite crystals have precipitated and entailed a secondary porosity.

One of the sandstones is Fontainebleau sandstone (HF). It is composed of more than $99 \%$ of quartz. Its porosity is low (4.6\%). The two other sandstones are two layered sandstones from India: the brown sandstone (MS) and the green sandstone (VS), two commercial varieties of the Agra sandstone. They are composed mostly of quartz, but contain some clay which gives the general colour of the rock and the layering. These sandstones have a very high tensile strength (16.0 and $15.0 \mathrm{MPa}$ ) and low porosity (5.2 and 4.6\%).

The sandstones and the FL limestone have a detritic origin, and thus a quite simple porous network with only one main family of pores. This study will be mostly focused on these four stones, and then will compare the results obtained to a much more complicated stone: the biodetritic lutetian limestone LL. These five stones were chosen among the ones used in the experiments presented in Angeli et al. (2007) because they show a regular decay and their porous network can be easily studied. The mercury porosimetry tests have also been performed on two other sandstones presented in Angeli et al. (2007): a soft version of the Fontainebleau sandstone (SF) and a Chinese sandstone (CS). Due to their very low durability, it was not possible to take benefit of these data. Nevertheless, a thin section study of these stones has been performed to try to explain their low durability.

Total open porosity $\mathrm{P}(\mathrm{He})$ and grain density were characterised using mercury intrusion porosimetry (MIP) technique and helium pyknometer. Connected porosity $\mathrm{P}(\mathrm{Hg})$, bulk density, pore size distribution and mean pore radius were obtained in an Autopore IV 9500 Micromeritics mercury porosimeter. Pore size interval characterisation by MIP ranges from 0.006 to $200 \mu \mathrm{m}$, which corresponds to the highest and the lowest head pressures, respectively. In order to quantify porosity fraction below $0.006 \mu \mathrm{m}$, which can not be measured by MIP, total porosity was calculated. Total porosity $(\mathrm{P}(\mathrm{He}))$ includes open porosity 
and close porosity. Open porosity is the volume of pores accessible to any given molecule, and close porosity is the volume of isolated pores dispersed over the medium. It is important to mention here that connected porosity is the volume of pores accessible to a given molecule and depends on the technique used. Consequently, connected porosity is a fraction of the total open porosity.

The volume of the smallest pores (fewer than $6 \mathrm{~nm}$ ) has been estimated thanks to Helium pyknometry. Helium enters in the porous network as a gas, and thus has access to more pores than mercury which, as a liquid, has a higher surface tension. The difference between the two values of porosity obtained gives the submicroporosity (Dei et al. 1999). For each stone, the bulk and grain densities from mercury porosimetry have been used, as well as the grain density obtained by an AccuPyc 1330 Helium pyknometer. Equation (1) gives the value of the connected porosity from mercury porosimetry $\mathrm{P}(\mathrm{Hg})$, and equation (2) gives the value of the total open porosity. The submicroporosity is expressed as a percentage of $\mathrm{P}(\mathrm{He})$ after equation (3).

$\mathrm{P}(\mathrm{Hg})=100 *(1-\mathrm{d}($ grain,Hg)/d(bulk,Hg) $)$

$\mathrm{P}(\mathrm{He})=100 *(1-\mathrm{d}($ grain,He $) / \mathrm{d}($ bulk,Hg) $)$

Submicroporosity=1-P(Hg)/P(He)

Obviously this value cannot be precisely defined since the mercury porosimetry measurements are not as accurate as the helium pyknometry measurements. Nevertheless, the given values can be interpreted as reliable trends, since the bulk and grain densities have been measured on at least five different fresh samples for each stone. Submicroporosity is low for the two stones with large grains $(0.0 \%$ for HF and $4.5 \%$ for FL), and higher for the three other stones (12.3\% for MS, $10.4 \%$ for VS and $16.3 \%$ for LL). This means that the proportion of very small pores (under $6 \mathrm{~nm}$ ) is higher in the latter stones. These values are confirmed by the fact that the spectra for these three stones are open on the left side of the spectrum, suggesting pores with entry smaller than $6 \mathrm{~nm}$. These very high values are due to the fact that the two Agra sandstones are highly compacted with very small pores. For the liais LL, this high submicroporosity could result from the secondary micrite reducing the mean pore entry size of this stone, but could also be exaggerated due to the heterogeneities from one sample to the other.

Four of these stones have a relatively simple mercury porosimetry spectrum with most of the pore entry size around a mean value: $0.03 \mu \mathrm{m}$ for MS, $0.06 \mu \mathrm{m}$ for VS, $3 \mu \mathrm{m}$ for HF and $10 \mu \mathrm{m}$ for FL. The last stone, LL, shows several pore entry sizes from 0.01 to $20 \mu \mathrm{m}$, with 3 main peaks at around $0.1,1$ and $5 \mu \mathrm{m}$. It should be noted that the porosity due to diagenesis for the two limestones (LL and FL) is present in both mercury porosimetry spectra as a peak at around $0.150 \mu \mathrm{m}$ with a height of approximately $0.40 \mathrm{ml} / \mathrm{g}$. For the five different stones, there is a final peak in the spectra at around $100-200 \mu \mathrm{m}$. The height of this peak varies from 0.005 to $0.02 \mathrm{ml} / \mathrm{g}$. This is due to the fact that the rocks are composed of grains (or fossils for LL), and the interstices between grains fall into the range of $100 \mu \mathrm{m}$. Nevertheless, according to all the theories about salt crystallization (Scherer 2004; Steiger 2005a,b; Coussy 2006), no damage should occur in such big pores.

The capillary coefficient has been obtained by using the EN 1925 European standard test. The tensile strength has been evaluated with Brazilian tests. The evaporation coefficient has been obtained similarly to the capillary coefficient: it is expressed as the slope of the graph presenting the weight increment divided by the evaporation surface as a function of the 
square root of time. In this plot, phase 2, which depends mainly on the characteristics of the stones and less on the environmental conditions, is linear (Hammecker 1993). The reason why this evaporation coefficient is used instead of the usual coefficient (linear coefficient of weight loss as a function of time during phase 1) is because this coefficient is independent of the environmental conditions, which is not the case for the usual coefficient.

Complete hydromechanic properties of these seven sedimentary rocks are given in table 1. The Alteration Indices (AI) and Velocities (AV) introduced by Angeli et al. (2007) are also reported in order to evaluate the durability of these stones. For recall, AI corresponds to the moment where the first visual damage appears. This means that the most durable stones have a high AI and a low AV.

The salt used in this study in sodium sulphate for practical reasons. This salt is known as the most destructing salt regarding accelerated ageing tests; hence noticeable results are obtained easily. This is the reason why it has been widely studied before, and the damage mechanisms are rather well known (e.g. Rodriguez-Navarro and Doehne 1999, RodriguezNavarro et al 2000, Lopez-Arce and Doehne 2006, Ruiz-Agudo et al 2007).

\section{Methods}

\section{Experimental weathering test}

The durability of the rocks has been tested according to the EN 12370 standard (1999) about stone resistance to crystallization of salts in pores. The samples are cylinders of $2.5 \mathrm{~cm}$ diameter and $4.5 \mathrm{~cm}$ height, and two samples have been used for each stone. The test is composed of cycles which last 24h:

- 2 hours of immersion in a saturated solution with respect to sodium sulfate;

- 15 hours of drying at $105^{\circ} \mathrm{C}$ in order to prevent mirabilite crystallization during drying of the samples;

- 7 hours of cooling at room temperature $\left(20-25^{\circ} \mathrm{C}, 30-40 \%\right.$ relative humidity $\left.\mathrm{RH}\right)$. The samples were weighed after 2 hours during this stage.

Since the experimental conditions are similar for all the samples (type and quantity of salt, environmental conditions), the only difference of weathering between the samples comes from the microstructures.

\section{Characterization of the samples}

First, a slice of $0.5 \mathrm{~mm}$ thickness approximately has been taken from the fresh samples, and the pore size entry distribution has been obtained. Then, fifteen cycles have been performed on the remaining part of the samples. Sample weight has been monitored during the experiment in order to have an idea of the evolution of the decay. After 15 cycles, a slice of the more damaged sample of each stone type has been removed and cut into halves. This slice has been cut on the side where the first fresh slice has been taken before the beginning of the tests, in order to limit the impact of the natural variability of the stones. The distribution of the porous network of one half was measured directly with mercury porosimetry. For the other half, the salt has been removed before the mercury porosimetry test was performed.

To remove the salts from the samples, they have been immersed in distilled water at $50^{\circ} \mathrm{C}$ to prevent damage during cleaning, and the water was changed every day. Electrical 
conductivity of the water used to wash the samples was monitored to follow its degree of saturation, since the concentration of sodium sulphate in the solution has a significant influence on it. After the first days of cleaning, it was reaching values up to several hundreds of $\mathrm{mS} / \mathrm{m}$. The samples were considered clean when the electrical conductivity was stable around $0.3 \mathrm{mS} / \mathrm{m}$ while deionised water had a conductivity of $0.1 \mathrm{mS} / \mathrm{m}$. The spectrum values for the fresh, weathered and clean samples of the five stones are presented on table 2 .

For all the mercury intrusion porosimetry measurements, the mercury-solid contact angle has been set to $130^{\circ}$ which is typical for most solids (Good and Mikhail 1981). The effect of the presence of salt in the weathered samples measurement has been neglected, although the mercury-salt and mercury-stone contact angles are certainly different (RuizAgudo et al 2007).

Thin sections of the fresh stones have been observed to complete the mercury porosimetry measurements, as well as SEM observations of clean and weathered samples.

\section{Influence of salt crystallization on mercury porosimetry data}

First and foremost, it is important to work with mercury porosimetry data using volume data and not percentage data. Results show that the global porosity of the samples changes during the tests. The porosity decreases with the presence of crystallized salts, and rises with the creation of cracks with propagation of existing cracks and with enlargement of pores. Therefore the only good comparison of the porous spaces is with volume of mercury intrusion.

We will first assume that the porous network is not modified during the final dissolution of the salts, which aims to clean the samples. We can think that while we add pure water in the samples at a temperature higher than $32.4^{\circ} \mathrm{C}$ (temperature limit of mirabilite stability), mirabilite precipitation is prevented and thus no damage is done to the porous network during the progressive desaturation of the samples. So all the modification observed on the porous network occurred before the final dissolution of the salts. Stresses are released when a crystal is dissolved and the void (pore or microcrack) in which it lies can close down after the dissolution. But it will not change anything on the mercury porosimetry data, since in both cases we will see this void neither with the crystals (void filled) nor without the crystals (void closed). Let us now consider different mechanisms which might affect the MIP spectra.

Case 1: If the pore entry is obstructed (fig. 1a), the entire pore volume is seen by the device with a lower diameter, hence the peak will shift to lower values and the global porosity value will remain almost unchanged. (fig. 1b)

Case 2: If crystals grow inside the pore (fig. 2a), the pore entry size is not modified, but the global volume will appear smaller. The volume attributed to this size of pore entry will be lower. In both cases, since we assume there were no cracks induced by the crystal growth, the pore volume should rise back to its original value after the final dissolution. (fig. 2b)

Case 3: Most of the time the last two features are observed at the same time, that is to say the crystals both obstruct the entrance and diminishes the volume inside the pores (fig. 3a, b). It should be noted that, if some of the pores are completely blocked, Case 3 cannot be distinguished from Case 1. That is to say there could be precipitation exclusively in small 
pore entries, but the pore volume would drop because some large pores are sealed off by complete blocking of their entries.

Case 4: If crystals grow in the porous network, create cracks and fill them entirely (or at least their entry), these cracks will not be seen in the altered stone spectrum. Hence, once the samples are clean from their salt, these new cracks will appear in the spectrum (Fig. 4). These microcracks have been of course only discovered after the dissolution, and not induced by this dissolution. Nevertheless, there can be other interpretations for figure 4. This situation can also happen if the lower pore entry sizes correspond to micropores and not microcracks. In this case, this situation could be interpreted as an exaggeration of the ink bottle phenomenon: the weathering would have caused an increase of the pore chamber without changing the pore entry size (fig. 5). This can be due for instance to salt-induced dissolution. This new porosity could also result from the formation of porous aggregate of thenardite from dehydration of mirabilite after the oven drying of the samples (Ruiz-Agudo et al. 2007). This type of porosity would be observed only when salt is in the sample, for the weathered sample, but not on the fresh and clean samples.

Case 5: If crystals grow in a pore and widen its entry, by forming a crack nucleated by the entry for instance, there will be no noticeable variation of pore entry size between fresh and weathered (fig. 6a). But once the salts are dissolved, the entrance will appear bigger, and this will be represented on the spectrum like on figure $6 \mathrm{~b}$.

It is easier to work on rocks with a unimodal distribution of pore size entry (HF, MS, VS, FL), and thus these stones will be studied first in order to find the main common characteristics. Afterwards, these results will be compared to a much more complicated stone (biodetritic limestone LL) and check the common features.

\section{Relevance of the method}

A preliminary study has been performed to test the reproducibility of the mercury injection tests and therefore the relevance of the proposed method. Three fresh samples of each stone have been taken in the exact same conditions than described in the "Characterization of the samples" part, that is to say two adjacent slices of a single cylinder. The samples obtained contain absolutely no salt, and have a volume of approximately $3 \mathrm{~cm}^{3}$. Figure 7 shows the spectra of the three samples for each stone. The spectra for the Fontainebleau sandstone (fig 7a), the two Agra sandstones (fig. 7b,c) and the detritic limestone (fig. 7d) clearly demonstrates that, for these four stones, natural variability is negligible. For the biodetritic limestone (fig. 7e), the situation is a bit different. The peak at around $0.150 \mu \mathrm{m}$ is present on the three spectra, although a bit fuzzier than for the other stones. Thus major modifications concerning this peak can be interpreted as effect of salt crystallization. Nevertheless, the pores with entries bigger than $1 \mu \mathrm{m}$ are quite different in the three spectra. Even though the values are quite similar, their distribution has a too big natural variability to be studied. Finally, these results show that the spectra are similar enough to make sure the differences observed between weathered, clean and fresh samples are meaningful (except for the pores with entry bigger than $1 \mu \mathrm{m}$ for LL). 


\section{Results}

\section{Porosity changes}

The first thing to notice is that the evolution of the total porosity before and after the tests is reliable: for all the samples, the porosity is higher for the weathered and cleaned samples than for the fresh samples. This confirms the fact that some cracks or pores in the samples have been created or enlarged by the crystallization pressure of sodium sulphate. Secondly, the porosity is higher for the weathered and cleaned sample than for the weathered samples with salt. Obviously the presence of salt in the pore space reduces the porosity of the samples. The only type of rock that does not exactly respect these two rules is the bioconstructed limestone LL. This is due to the global heterogeneity of the samples coming from its high amount of macrofossils.

Table 3 presents the changes of porosity due to the crystallization of salts in the porous networks. The first values correspond to the space occupied by thenardite during the measurements of mercury porosimetry, that is to say under vacuum. The second value is an approximation of the equivalent volume occupied by mirabilite during the imbibition phase, taking into account the $314 \%$ of volume raise. The third value corresponds to the porosity evolution before and after the test, that is to say the augmentation of porosity due to salt decay.

\section{Size of the microcracks}

In order to find the approximate size of the cracks induced by salt crystallization, mercury porosimetry spectra obtained from the fresh samples and from the altered samples after salt cleaning will be compared. As we assume there is no more salt in the sample after cleaning, the difference between the two spectra comes from the formation of cracks.

The method consists in pointing the areas where the spectrum of the fresh sample lies under the spectrum of the altered sample: this represents the pore size entry for which the volume has risen during the accelerated ageing test. This method is directly drawn from the mercury porosimetry analysis presented in the last part. Since the porosity of the five types of stones is quite different, the vertical scale of the graphs is different from one stone to another to make the figure easier to read.

First, for the porous network of HF (fig. 8a), the family of pores whose entries seem to have widened during the test ranges from $3 \mu \mathrm{m}$ to $15 \mu \mathrm{m}$ (case 5). It is important to recall that the size of the main family of pore entry is still around $3 \mu \mathrm{m}$ after the test. Nevertheless, this variation appears like a step, and then the spectrum continues with the same slope as before the step: this could also be due to a too small equilibrating time during the mercury porosimetry test. The secondary peak around $0.35 \mu \mathrm{m}$ corresponds to the nucleation or widening of cracks (case 4). It should be also noted that the spectra presented here are slightly different from those presented on figure 7a: there is an unexpected low value of volume for entry around $2 \mu \mathrm{m}$. But since this low value is present on the three spectra, it is considered as a local variability of the natural stone, and not as an effect of salt.

The second stone, MS (fig. 8b), shows a main family of pore entry at around $0.05 \mu \mathrm{m}$ for the fresh facies. The volume corresponding to the main pore entry size of this family 
diminishes a bit and the lower pores of this family have risen in volume: salts have crystallized in these pores (case 2). The secondary new peak at around $0.02 \mu \mathrm{m}$ corresponds to the creation of cracks (case 4).

In the third stone, VS (fig. 8c), the main family of pores in the fresh stone is around $0.06 \mu \mathrm{m}$. The smallest new microcracks have a size around $0.01 \mu \mathrm{m}$, (case 4). On the other hand, some pores from 0.06 to $0.1 \mu \mathrm{m}$ have been extended (case 5). A new family of microcracks seem to have appeared in the range $0.2-10 \mu \mathrm{m}$ (case 4).

For FL limestone (fig. 8d), the main pore entry size is much larger than for the three sandstones: $10 \mu \mathrm{m}$. A new family of cracks from 0.03 to $0.3 \mu \mathrm{m}$ has appeared or existent cracks of this size have widened (case 4).

For LL limestone (fig. 8e), the range of pore entry of the fresh stone is particularly wide, from $0.01 \mu \mathrm{m}$ to $20 \mu \mathrm{m}$. The only major difference between the samples before and after the test concerns the pores with entries from 0.006 to $0.03 \mu \mathrm{m}$ which seem to have doubled in volume (case 4). Nevertheless, considering the results of the relevance test (fig. 7e) could lead to match these variations to the natural heterogeneity of this stone. A few other cracks seem to have appeared here and there in the whole range of pore size entries but the natural heterogeneity due to macrofossils of the stone prevents us from drawing any conclusion.

\section{Location of sodium sulphate crystals}

In order to find the places of sodium sulphate crystallization, the results of mercury porosimetry for the samples that have been altered, before and after removing the salt by dissolution, will be compared (fig. 9). The difference between the two samples is related to the salts that have been dissolved. In addition, the difference between the two distributions of pores for a same stone will help to understand where sodium sulphate does crystallize in the porous network.

The method consists in finding where the spectrum of the cleaned stone is over the other. This gives the entry sizes of pores in which the crystals lie. Then correlating this finding with the zones where the spectrum of the cleaned stone is below the other allows us to find if the crystals have filled the pores, obstructed and/or widen their entries.

For all these stones, the porosity is reduced from 2.2 (VS) to $8.15 \%$ (FL) by the presence of thenardite. Although sodium sulphate is a very destructive salt, this confirms that it does not occupy much room, when under the thenardite form, in the porosity of the stone compared to other salts: around 55\% for sodium chloride (Rodriguez-Navarro and Doehne 1999) or around 25\% for magnesium sulfate (Ruiz-Agudo et al 2007). Nevertheless, this observation is done on the final state of the samples. This is not an image of the microstructures and salts during the wetting stage during which the damage. First, it must be kept in mind that the salt present in the pores during the mercury porosimetry measurements is thenardite, but the damaging phase of sodium sulphate is known to be mirabilite (Tsui et al 2003). Thus the volume of salt during the damaging phase is approximately three times higher than the volume of salt observed with this technique, that is to say 6.5 to $24.5 \%$ of equivalent mirabilite occupy the pore space of the stones during imbibition (Table 3). Second, during the capillary part of evaporation, the water flowing in the pores towards the surface changes the distribution of the salt crystals in the porous network by remobilizing them (Angeli et al. 2006). 
First, in the porous network of HF (fig. 9a), there are three main sizes of pores which the crystals seem to have filled: $0.2-0.6 \mu \mathrm{m}, 3-5 \mu \mathrm{m}$ and $10-15 \mu \mathrm{m}$. These sizes correspond exactly to the pore entries which seem to have been widen during the experiments. They also do not have a corresponding lower peak of uncleaned stone, which means that these crystals have obstructed the pores they lie in, as well as their entry (case 1).

Second, for MS (fig. 9b), the peak has shifted from 0.06 to $0.03 \mu \mathrm{m}$, with a very small diminution of the global volume. This means that the salt have crystallized in the main family of pores, and obstructing their pore entry (case 2). Nevertheless, since the height of the peak is almost the same, we can assume that the volume occupied by the salt in these pores is very small compared to the global porosity.

For VS (fig. 9c), we can notice a volume diminution of the main peak, and a blister towards the smaller pore entry sizes. This means that a large amount of pore entries of this size have been reduced from 0.06 to $0.03 \mu \mathrm{m}$, thus obstructed by salts (case 3). Once again, the volume is almost the same for the two spectra, meaning that the volume of salt in the pores is very small even though it reduces significantly the size of the pore entries.

Mercury porosimetry spectra of FL (fig. 9d) show the same pattern as for VS, i. e. a decrease of the main peak and a blistering to the smaller values. This corresponds to the partial obstruction of the pore entries by salt crystals (case 3), reducing these entries from $10 \mu \mathrm{m}$ down to $6 \mu \mathrm{m}$. SEM observations from the porous network on an altered sample of FL (fig. 10) show that walls of calcite grains are coated with salt crystals. According to its size, salt coating could be responsible for this reduction of the void size approximately from $12 \mu \mathrm{m}$ to $6 \mu \mathrm{m}$. There are also few pores around $0.2 \mu \mathrm{m}$ whose entry seems to be obstructed by crystals.

Finally, for LL (fig. 9e), if we consider the hypothetical new microcracks from $0.005 \mu \mathrm{m}$ to $0.03 \mu \mathrm{m}$ that were created during the test, it appears that they are filled with salt crystals (case 1). Some crystals also fill up few pores from the main family, around $0.1 \mu \mathrm{m}$, and slightly obstruct the entrance (from $0.1 \mu \mathrm{m}$ to $0.08 \mu \mathrm{m}$ ). Nevertheless, the high natural heterogeneity of this stone should be kept in mind when interpreting these results. In the whole range of remaining pores, from $0.5 \mu \mathrm{m}$ to $20 \mu \mathrm{m}$, here and there crystals are filling pores but the heterogeneity of the stone prevents us from drawing any reliable conclusion.

\section{Discussion}

First it is important to recall two important points of this study: first, it deals only with damage related to sodium sulphate; second, what is observed on mercury porosimetry and SEM is only the dry state of the porous network, and the damage with sodium sulphate appears during the imbibition of the stones, while the dissolution of thenardite entails a supersaturation of the brine with respect to mirabilite (Flatt 2002, Tsui et al 2003).

In the experiments discussed in this paper, that is to say when damage is due to imbibition and drying cycles, the crystallization occurs during wetting, when the invading water dissolves thenardite and causes mirabilite precipitation (Flatt 2002). Therefore, the crystals probably form in pores of all sizes and grow so quickly that equilibrium cannot be preserved. The damage then occurs under nonequilibrium conditions analogous to those created during cooling of a saturated solution (Scherer 2004; Steiger 2005a,b). Since 
supersaturation of the brine is rapidly similar in pores of all sizes due to diffusion, the higher crystallization pressures should occur in the smallest pores of a stone. This result corroborates the fact that according to numerous studies (e. g. Russell 1927; Schaffer 1932; RodriguezNavarro and Doehne 1999; Scherer 1999), the stones that are the most susceptible to salt decay are, all other factors equals, the one with the highest proportion of small pores.

Let us have a look now on the durability of the tested stones. The most damaged stone is by far FL (tab. 1). It has the lowest AI and an AV up to 10 times higher than the second less durable stone. Then the second most damaged is VS, then LL and finally the two others with a very similar durability (MS and HF). Figure 10 presents the final state of samples after 15 cycles. Note that the samples presented here are cubes and not cylinders: these samples have been experimentally weathered in the same time than the cylinders, as explained in Angeli et al (2007). They are presented here just because the state of weathering is more obvious on these samples. It is also important to recall that the samples were not in the same state of decay when they have been measured, but they have all experienced the same number of cycles (15) when the mercury porosimetry tests have been performed.

Let us consider now the quantity of pores with entries under $100 \mathrm{~nm}$. The stones with the most pores of this size are MS and LL (resp. 0.0128 and $0.0126 \mathrm{ml} / \mathrm{g}$ ), then VS $(0.0082 \mathrm{ml} / \mathrm{g})$ and finally FL and HF which almost do not contain pore with entry less than $100 \mathrm{~nm}$ (resp. 0.0005 and $0.0001 \mathrm{ml} / \mathrm{g}$ ). If we consider the quantity of pores with entries under $1 \mu \mathrm{m}$, the stone with the most pores of this size is LL $(0.0356 \mathrm{ml} / \mathrm{g})$, then FL and MS (resp. 0.0156 and $0.0140 \mathrm{ml} / \mathrm{g})$, VS $(0.0102 \mathrm{ml} / \mathrm{g})$ and $\mathrm{HF}$ which again contains very few pores with entry under $1 \mu \mathrm{m}(0.0015 \mathrm{ml} / \mathrm{g})$. This would lead us to think that the most weathered stone would be LL, then MS, VS and FL almost with the same proportion of small pores, and finally HF should be the least altered stone. These expectations seem a bit different than the actual durability obtained by the experimental ageing. Obviously the durability of HF and VS, which have the same porosity (4.6\%), fit very well with this interpretation since VS has much more micropores than HF. It is not so clear for the three other stones, but other facts have to be taken into account.

First, these figures have to be counterbalanced by the fact that FL is much more porous than the other stones, and has a much faster the capillary flow in its porous network (tab. 1). Thus salt uptake is faster for this stone, implying a faster supersaturation of the brine with respect to mirabilite by dissolution of thenardite. This seems to be a reliable explanation for the very low durability of FL. LL, which has a high porosity of $17.0 \%$ and the most micropores of all five stones, has a porous network which is very different from those of the four other stones. Its nature of biodetritic limestones gives not only a very heterogeneous aspect, but also a very chaotic porous network. The components of this stone are fossils of very different sizes and shapes, hence the pores have also a high natural variability. Diagenesis-induced calcite reprecipitations should also not be forgotten. All these reasons should certainly imply a porous network with high tortuosity and low connectivity. This certainly also implies a very bad fluid flow in the porous network, and explains the high durability of this stone.

Figure 11 presents a summary of the data collected about the microcracks which seem to have appeared during the accelerated ageing test, and about the supposed location of sodium sulphate crystals. 
For FL, HF and VS, the mercury porosimetry data indicate that crystals have grown in the pore entries and chambers of the three respective main families of pores. This MIP pattern (case 3, fig. 3b) is very similar to what can be observed on the spectra from RodriguezNavarro and Doehne (1999) and from Ruiz-Agudo et al (2007). It is very clear for FL and VS. For HF, the shape of the spectra are different (case 1) but, as explained above, case 1 and 3 are very similar and cannot be always distinguished. SEM observations of the inner part of the porous network of the FL weathered sample (fig. 12) tend to confirm that crystals grow in pore of all sizes: crystals can be seen on all the grain surfaces regardless of the pore size. These crystals seem to result from the crystallization of thenardite on all pore walls during drying.

It seems to be a little different for MS. There seem to be apparently only salt crystals in the pore entries, but not in the pore chamber. A probable explanation would be that the "ink bottle" effect is less important in its porous network than in the three other stones. This means that its pores are closer than usual to the classical cylindrical pore model. This could be related to the unexpected high specific surface area of MS $\left(3.59 \mathrm{~m}^{2} / \mathrm{g}\right)$ as a comparison to VS $\left(1.25 \mathrm{~m}^{2} / \mathrm{g}\right)$ which has very similar porosity and pore size entry distribution. This could explain also the higher durability of MS: these cylindrical pores limit the number of sites where micropores are connected to macropores, sites where the highest crystallization pressure are expected (Scherer 2004).

Finally, for LL, it is very difficult to draw any conclusion on the location of the sodium sulphate crystals, given its very high natural variability. The only thing that can be noticed is that the peak at approximately $150 \mu \mathrm{m}$ does not seem much affected. Thus it appears that, due to the very bad fluid flow in its porous network, crystallization of salts is quite difficult in this range of pore size. This could explain the high durability since the highest crystallization pressures occur in the small pores (Correns 1949; Benavente et al. 1999; Scherer 2004; Steiger 2005a,b; Coussy 2006). But this result has to me considered as a hypothesis since more precise studies are necessary for this complicated stone.

Thus, it seems that sodium sulphate crystallizes in almost any size of pore entries from 0.01 to $20 \mu \mathrm{m}$. All the pore sizes in a given stone seem to be affected by the crystallization of sodium sulphate, as confirmed by SEM observations (fig. 12). Indeed grains appear entirely coated with sodium sulphate crystals. The presence of crystals in all the possible pore sizes makes both mechanisms of decay possible (equilibrium and non-equilibrium).

These observations are confirmed by the fact that, in the five studied stones, preexistent pores and cracks have been affected. This means that the pores of all entry sizes are damaged. This is consistent with Steiger (2005) who concluded that crystals can grow not only in the smaller pores $(0.01-0.05 \mu \mathrm{m}$ and lower) and damage them permanently in a thermodynamically equilibrated situation (Scherer 2004), but also in the larger pores (up to several $\mu \mathrm{m}$ ) and damage them during their growth, in a non-equilibrated situation.

Thus, the more available surface in the porous network, the better opportunity for salt to crystallize and damage the rock. In particular, the presence of numerous cracks in the stone could explain the unexpected vulnerability of a rock to salt decay (Nicholson 2001). In a previous work (Angeli et al. 2007), the behaviour of nine sedimentary stones towards salt weathering has been evaluated. For only two stones, CS and SF, the durability was wrongly estimated: the authors expected a very high durability and found out that the stones were severely decayed by salt damage. These stones have also been tested in this study, but the 
samples were so severely damaged that they crumbled in the mercury porosimetry chamber. After an analysis of thin sections of each fresh stone they appeared to be the only two stones with extensive intragranular cracking. The crack density estimated was relatively high (63.2 cracks $/ \mathrm{mm}^{2}$ for SF and 82.6 cracks $/ \mathrm{mm}^{2}$ for CS), while it was close to zero for the other stones tested in this study. The high density of cracks can explain why the two varieties of Fontainebleau sandstones, HF and SF, have such a different durability despite of their similar hydromechanical behaviour (Fig. 13).

This could be a reason to think that case 4, the volume raise for the lowest pores available in a stone, would correspond to an increase of the length of the pre-existent cracks rather than a creation of new microcracks. The nucleation of cracks does certainly happen, but the increase of the length of the pre-existent cracks seems to be an important factor that entails the unexpected weathering rate of SF and CS. It would confirm the fact that crystallization of salts would be thermodynamically easier and more destructive when occurring at the tip of a pre-existent crack or strength limiting flaw (Scherer 1999, Flatt 2002). This is in agreement with the fact that heterogeneities, and particularly cracks, act as local weaknesses and localizers of damage in rock mechanics. This allows us to complete the evaluation of durability proposed in Angeli et al. (2007): an important parameter influencing AV is thus the crack density. A precise study of the crack density on thin sections should give a more precise value for the estimator of $\mathrm{AV}$, that is to say the estimator of the long term behaviour of the stone regarding salt decay.

\section{Conclusion}

The first important conclusion is that there is no significant change in the porosity during the weathering process: the global porosity of the samples as well as the distribution of their pore size entry has not drastically changed between the fresh sample and the clean samples. As described in Rodriguez-Navarro and Doehne (1999), the sodium sulphate crystals in anhydrous phase do not seem to fill much of the pores (up to 8\% of total porosity) at the end of the experiment. Nevertheless, this volume rises to $24 \%$ of total porosity approximately if we consider the volume of mirabilite during the damaging imbibition phase, which is almost the amount of volume occupied by magnesium sulphate in the calcarenite at the end of the experiment described by Ruiz-Agudo et al (2007).

Second, most of the pores seem to be affected by the crystallization of salts, since in all the studied stones pores from $10 \mathrm{~nm}$ up to $20 \mu \mathrm{m}$ of entry have been affected during the accelerated ageing tests. SEM observations as well as mercury porosimetry spectra analysis suggest also that sodium sulphate tends to crystallize on all the grain surfaces regardless of the size of the related pore. Thus, this study confirms the work of Scherer (2004) and Steiger (2005) about the fact that a crystal growing (thus not in equilibrium) in a pore of size up to several $\mu \mathrm{m}$ can exert a crystallization pressure high enough to nucleate or propagate cracks in a porous network.

As a consequence this study confirms the fact that the stones with a high amount of small pores (up to several $\mu \mathrm{m}$ ) are more susceptible to decay, but still introduces some issues: for instance a very high porosity (case of FL) or an uncommon porous network (high tortuosity and low connectivity for LL, or cylindrical pores for MS) can also have an influence on the durability of stones. 
It has been established numerous times that the hydric properties of stones as well as their tensile strength are the critical parameters governing the durability of stones to salt decay, and these parameters are widely used to estimate this durability (Punuru et al. 1990; Benavente et al. 2004b; Angeli et al 2007). This study suggests the importance of pre-existent cracks on the durability of stone regarding salt decay. The presence of cracks is absolutely not necessary for the damage through salt decay, but it seems to greatly accelerate the process in the long term. This would confirm experimentally the theory saying that crystallization of salts would be thermodynamically easier and more destructive when occurring at the tip of a pre-existent crack or heterogeneity (Scherer 1999). This justifies the proper use of the P-wave velocity as a good estimator of the long term durability of a stone regarding salt decay: this velocity depends of course on the mineral composition of the stone, on its cohesion or mechanical strength, on its porosity, but the crack density also has a strong influence on it (Jeffreys 1931, Hudson 1981). Thus measuring the intragranular crack density of a fresh stone on thin sections, in addition to the other usual petrophysical tests (porosity, capillarity, tensile strength, pore size entry...), allows having a better estimation of its durability.

\section{Acknowledgements}

The authors would like to thank M. Pallix from ROCAMAT (Saint-Maximin-surOise) for providing LL and FL, M. Oliveira (Moigny-sur-Ecole) for the other samples, Manuel Palomo (Alicante) for preparing the sample, Irene Martin (Alicante) and Fabien Piguet (Cergy) for performing most of the mercury porosimetry measurements, and the two anonymous reviewers for their comments which greatly helped to improve this paper.

\section{References}

Angeli M, Bigas JP, Menéndez B, Hébert R, David C (2006) Influence of capillary properties and evaporation on salt weathering of sedimentary rocks - in "Heritage, Weathering and Conservation”, Edité par R. Fort, M. Alvarez de Buergo, M. Gomez-Heras \& C. VazquezCalvo, Taylor \& Francis/Balkema, AK Leiden, The Netherlands, 2006, 253-259

Angeli M., Bigas JP, Benavente D, Menéndez B, Hébert R. and David C. 2007 - Salt crystallization in pores: quantification and estimation of damage - Environmental geology, $52: 205-214$

Benavente D., Garcia del Cura M. A., Fort R. and Ordoñez S. 1999 - Thermodynamic modelling of changes induced by salt pressure crystallization in porous media of stone Journal of Crystal Growth, 204:168-178

Benavente D, García del Cura MA, García-Guinea J, Sánchez-Moral S, Ordoñez S (2004a) The role of pore structure in salt crystallisation in unsaturated porous stone. Journal of Crystal Growth 260:532-544

Benavente D, Garcia del Cura MA, Fort R, Ordoñez S (2004b) Durability of porous building stones from pore structure and strength. Engineering Geology 74:113-127

Correns C. W. 1949 - Growth and dissolution of crystals under linear pressure, Discuss. Faraday Soc., 5:267-271 
Coussy O. (2006) - Deformation and stress from in-pore drying-induced crystallization of salt. Journal of the Mechanics and Physics of Solids 54:1517-1547

Dei L., Mauro M., Baglioni P., Manganelli Del Fà C. and Fratini F.. 1999, Growth of Crystal Phases in Porous Media, Langmuir, 15:8915-8922

EN 12370 (1999) Natural stone test methods - Determination of resistance to salt crystallization. 1999-03

Everett D. M.1961 - The thermodynamics of frost damage to porous solids - Transactions of the Faraday Society, 57:2205-2211

Fitzner B. and Snethlage R. 1982 - Uber Zusammen Hange Zwischen Saltzkristallisationsdruck und porenradienverteilung, GP Newsletter, 3:13-24

Fitzner B 1988 - Porosity properties of naturally or artificially weathered sandstones - Proc VIth international Congr on Deterioration an d Conservation of Stonee, Torun, 12-14 Sept 1988, 236-245

Flatt RJ (2002) Salt damage in porous materials: how high supersaturations are generated. Journal of Crystal Growth 242:435-454

Good RJ, Mikhail RS (1981) The contact angle in mercury intrusion porosimetry. Powder Technol 29:53-62

Hammecker C 1993 - Importance des transferts d'eau dans la dégradation des pierres en œuvre, Ph.D. Thesis, University Louis Pasteur of Strasbourg, France

Honeyborne D. B. and Harris P. B.1958 - The structure of porous building stones and its relation to weathering behaviour - in Everett D. H. and Stone F. S. (Eds), Proceedings $10^{\text {th }}$ Symposium of the Colston Research Society, Butterworths Scientific Publications, London, 343-365

Hudson J. A. 1981 - Wave speeds and attenuation of elastic waves in material containing cracks - Geophys. J. R. astr. Soc. - 64:133-150

Jeffreys H. 1931 - Damping in bodily seimsmic waves - Mon. Not. R. astr. Soc. Geophys. Suppl. - 3:318-323

Lopez Arce P. and Doehne E. 2006 - Kinetics of sodium sulphate efflorescence as observed by humidity cycling with SEM - in "Heritage, Weathering and Conservation", Edité par R. Fort, M. Alvarez de Buergo, M. Gomez-Heras \& C. Vazquez-Calvo, Taylor \& Francis/Balkema, AK Leiden, The Netherlands, 2006, 285-291

Nicholson D. T. 2001 - Pore properties as indicators of breakdown mechanisms in experimentally weathered limestones - Earth Surface Processes and Landforms, 26:819-838

Punuru A. R., Chowdhury A. N., Kulshreshtha N. P. and Gauri K.L. 1990 - Control of porosity on durability of limestones at the Grat Sphinx, Egypt - Environmental Geology and Water Sciences, 15:225-232 
Rodriguez-Navarro C, Doehne E (1999) Salt weathering: influence of evaporation rate, supersaturation and crystallization pattern. Earth Surface Processes and Landforms 24:191209

Rodriguez-Navarro C, Doehne E, Sebastian E (2000) How does sodium sulphate crystallize? Implications for the decay and testing of building material. Cement and Concrete Research 30:1527-1534

Ruiz-Agudo E, Mees F, Jacobs P and Rodriguez-Navarro C (2007) The role of saline solution properties on porous limestone salt weathering by magnesium and sodium sulfates. Environmental geology 52:269-281

Russell, S.A. (1927) Stone preservation committee report. Appendix 1. H.M. Stationary Office, London

Schaffer R. J. 1932 - The weathering of natural building stones, DSIR, Building Research Special Report 18, Stationery Office, London, 34 pp.

Scherer G (1999) Crystallization in pores. Cement and Concrete Research 29:1347-1358

Scherer G (2004) Stress from crystallization of salt. Cement and Concrete Research 34:16131624

Steiger M 2005a - Crystal growth in porous materials-I: the crystallization pressure of large crystals. J Cryst Growth 282:455-469

Steiger, M. 2005b - Crystal growth in porous materials - II: Influence of crystal size on the crystallization pressure. Journal of Crystal Growth 282: 470-481

Winkler E. M. 1997 - Stone in Architecture - Springer Verlag, Berlin, 313 pp.

\section{Figures and tables}

Table 1: Hydromechanical and durability properties of the studied stones

Table 2: Evolution of the porosity corresponding to ranges of pore entry sizes before and after accelerated weathering

Table 3: Evolution of porosity during the tests

Figure 1a: Salt crystals obstructing a pore entry (Case 1)

Figure 1b: Interpretation on mercury porosimetry data of salt crystals obstructing a pore entry (Case 1)

Figure 2a: Salt crystals partially filling a pore (Case 2)

Figure 2b: Interpretation on mercury porosimetry data of salt crystals partially filling a pore (Case 2)

Figure 3a: Salt crystals obstructing a pore entry and partially filling it (Case 3)

Figure 3b: Interpretation on mercury porosimetry data of salt crystals obstructing a pore entry and partially filling it (Case 3)

Figure 4: Interpretation on mercury porosimetry data of the creation of microcracks or extension of microcracks without changing the pore entry (Case 4) 
Figure 5: Model explaining the increase in volume of a pore without increasing its pore entry (Case 4)

Figure 6a: Theoretical model of the widening of pore entry and filling of a pore (Case 5)

Figure 6b: Interpretation on mercury porosimetry data of the widening of pore entry and filling of a pore (Case 5)

Figure 7a: Mercury porosimetry spectra of three adjacent fresh samples $\left(\sim 3 \mathrm{~cm}^{3}\right)$ of Fontainebleau sandstone (HF).

Figure 7b: Mercury porosimetry spectra of three adjacent fresh samples $\left(\sim 3 \mathrm{~cm}^{3}\right)$ of brown Agra sandstone (MS).

Figure 7c: Mercury porosimetry spectra of three adjacent fresh samples $\left(\sim 3 \mathrm{~cm}^{3}\right)$ of green Agra sandstone (VS).

Figure 7d: Mercury porosimetry spectra of three adjacent fresh samples $\left(\sim 3 \mathrm{~cm}^{3}\right)$ of the detritic limestone called "roche fine" (FL).

Figure 7e: Mercury porosimetry spectra of three adjacent fresh samples $\left(\sim 3 \mathrm{~cm}^{3}\right)$ of the biodetritic limestone called "liais" (LL).

Figure 8a: Size of microcracks - HF

Figure 8b: Size of microcracks - MS

Figure 8c: Size of microcracks - VS

Figure 8d: Size of microcracks - FL

Figure 8e: Size of microcracks - LL

Figure 9a: Location of sodium sulphate crystals - HF

Figure 9b: Location of sodium sulphate crystals - MS

Figure 9c: Location of sodium sulphate crystals - VS

Figure 9d: Location of sodium sulphate crystals - FL

Figure 9e: Location of sodium sulphate crystals - LL

Figure 10: SEM picture of sodium sulphate crystals in a pore of FL

Figure 11: Weathering advancement of the five types of stones after 15 cycles

Figure 12: Summary of the location of sodium sulphate crystals in the porous networks of the five studied stones

Figure 13: Thin sections of two varieties of Fontainebleau sandstones with a similar hydromechanic behaviour and completely different durability: the weak stone on the right shows many intragranular cracks as opposed to the durable stone on the left 